$$
\text { Pontifícia Universidade C Católica }
$$

Leila Curty Siqueira Moreno Rosário

Inserção de Políticas de Propriedade Intelectual nas
Instituições de Ensino Superior: O Caso PUC-Rio

Dissertação de Mestrado

Dissertação apresentada como requisito parcial para obtenção do grau de Mestre pelo Programa de Pósgraduação em Administração de Empresas do Departamento de Administração da PUC-Rio.

Orientador: Prof. José Roberto Gomes da Silva

Rio de Janeiro

Março de 2006 


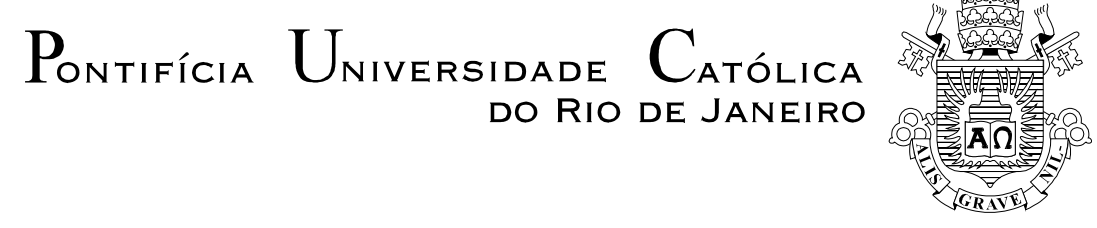

Leila Curty S. Moreno Rosario

\title{
Inserção de Políticas de Propriedade Intelectual nas Instituições de Ensino Superior: O Caso PUC-Rio
}

\begin{abstract}
Dissertação apresentada como requisito parcial para obtenção do grau de Mestre pelo Programa de Pósgraduação em Administração de Empresas da PUC-Rio. Aprovada pela Comissão Examinadora abaixo assinada.
\end{abstract}

Prof. José Roberto Gomes da Silva

Orientador

Departamento de Administração - PUC-Rio

Prof. Teresia Diana Lewe van Aduard de Macedo-Soares

Departamento de Administração - PUC-Rio

Prof. Adriane Monteiro Cavalieri Barbosa

Instituto Nacional de Tecnologia

Prof. João Pontes Nogueira

Vice-Decano de Pós-Graduação do CCS

Rio de Janeiro, 27 de março de 2006 
Todos os direitos reservados. É proibida a reprodução total ou parcial do trabalho sem a autorização da universidade, da autora e do orientador.

\section{Leila Curty Siqueira Moreno Rosário}

Graduou-se em Administração de Empresas pela Pontifícia Universidade Católica do Rio de Janeiro (PUC-Rio) em 2002. Desenvolve junto à Coordenação Setorial de Desenvolvimento do Decanato do Centro Técnico-Científico (CSD/DCTC) da PUC-Rio atividades de pesquisa em temas ligados à Gestão da Propriedade Intelectual no contexto Acadêmico, no âmbito do Escritório de Negócios e Propriedade Intelectual (ENPI) da PUC-Rio. É responsável pela Gestão FísicoFinanceira e Orçamentária de Projetos de Pesquisa e Desenvolvimento e na elaboração do (SIAP) Sistema de Informação para Gestão de Projetos. Participou da organização de eventos na área Tecnológica. É supervisora de Administração da CSD/DCTC. Publicou, no XXIX Encontro da Associação Nacional de Pós-Graduação e Pesquisa em Administração (EnANPAD), realizado entre 17 e 21 de setembro de 2005 em Brasília, o artigo "Pioneirismo e Mudança Organizacional: O Caso das Primeiras Aviadoras da Força Aérea Brasileira” e, no XXV Asamblea Anual Conselho Latino-Americano das Escolas de Administração (CLADEA), realizado entre 20 e 22 de outubro de 2005 em Santiago do Chile, Chile, o artigo "Managing Organizational Culture in a Small Family Business: Case Study Guapo Loco”.

Ficha Catalográfica

Rosário, Leila Curty Siqueira Moreno

Inserção de políticas de propriedade intelectual nas instituições de ensino superior: o caso PUC-Rio / Leila Curty Siqueira Moreno Rosário; orientador: José Roberto Gomes da Silva. - Rio de Janeiro: PUC-Rio, Departamento de Administração, 2006.

$136 \mathrm{f} . ; 30 \mathrm{~cm}$

Dissertação (mestrado) - Pontifícia Universidade Católica do Rio de Janeiro, Departamento de Administração

Inclui bibliografia

1. Administração - Teses. 2. Gestão Universitária. 3. Gestão do Conhecimento nas IES. 4. Gestão da Propriedade Intelectual. 5. Propriedade Intelectual. 6. Comercialização e Transferência de Tecnologia. 7. Inovação. I. Silva, José Roberto Gomes da. II. Pontifícia Universidade Católica do Rio de Janeiro. Departamento de Administração. III. Título. 


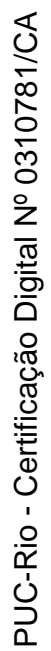

Aos meus filhos, Saimon e Eric, meus eternos amados. 


\section{Agradecimentos}

Primeiramente a Deus, por ter me dado forças que nem eu imaginava ter.

Ao Professor José Roberto Gomes da Silva, que além de um excelente orientador, tornou-se, um amigo, um conselheiro, um incentivador... poderia preencher uma folha inteira detalhando meus agradecimentos ele, mas o que me resta é dizer um muito obrigada pela paciência e carinho dispensados durante esta longa jornada.

Ao Professor Marcos Lopes Rego, por ter me encorajado a trilhar este caminho, por ter me mostrado que eu seria capaz... bem, acreditei e estou aqui o agradecendo.

A todos os Professores do Mestrado Profissional, que muito contribuíram, com seus ensinamentos e exemplos de dedicação, para meu desenvolvimento acadêmico e pessoal. Especialmente à Professora Patrícia Tomei e ao Professor José Roberto pela orientação para a publicação de dois artigos no decorrer do curso.

Aos Professores Paulo Cesar Motta e Fernando Rizzo que me proporcionaram as condições para fazer este curso. Não seria possível sem o auxílio deles.

Aos meus chefes Professores Fernando Rizzo, Pimenta-Bueno, José Alberto dos Reis Parise e Reinaldo Calixto, pela compreensão, estímulo e por terem permitindo a flexibilidade do meu horário de trabalho necessário ao cumprimento de minhas tarefas de mestranda.

À Shirley Coutinho, minha inspiração e exemplo de vida profissional, sempre me incentivando e orientando, me estimulando e apoiando nos momentos mais adversos de minha vida.

À minha assistente Joselli Dantas que me deu todo o suporte necessário à conclusão da minha dissertação. 
Aos meus colegas do Decanato do CTC, Marquinhos, Marcelo, Marco Lopes, Rodrigo, Allan, Bruno e Mário e as meninas, Renata, Santana, Eliane, Vera, Carmen, Mila e Patrícia. Obrigada a todos pela compreensão e auxílio em todos os momentos desses anos de interação.

Aos amigos da turma de 2003, em especial Bruno Pelluso, Jorge Araújo, Marco Brandão e Fabio Tauk com quem tive o prazer de compartilhar, em primeira mão, as aventuras desse processo de aprendizado. E, às amigas Flávia Schmidt, Ana Claudia Pinheiro, Patrícia Ferrari, Adriana Chaves, Christine Pina e Karine Karam com que tive a oportunidade de partilhar momentos ímpares no decorrer deste curso.

Ao pessoal da secretaria, Teresa, Leopoldo e Fábio, sempre atenciosos e cooperativos nesta jornada.

Ao meu amigo Alex Alves que muito me incentiva e, mesmo estando distante, está sempre presente em minha vida.

À minha amiga/irmã Márcia Pradanoff por todo apoio, carinho e companheirismo, mesmo sendo pessoas tão diferentes somos amigas para todos os momentos.

Aos meus familiares tios e primos que sempre estiveram presentes em minha vida e até hoje participam dela.

Aos meus pais que sempre me apoiaram, em todos os momentos de minha vida, que cuidam de meus filhos como se fossem seus filhos. A eles devo o que sou, o que penso e o que acredito, enfim, devo minha vida.

Aos meus queridos filhos, Saimon e Eric, por quem tenho toda admiração desse mundo, pois são filhos especiais, cada um com suas características, capazes de exprimir todo o sentimento de amor e carinho que sentem por mim. Meus meninos, tenho orgulho de ser mãe de vocês.

E a todos que não citei o nome, mas que sempre me incentivaram e torceram por mim. 
"O que posso te dizer? Voe!!! Você já viu um pássaro começando a voar? No início ele tem medo, se sente inseguro, bate as asas de modo desajeitado, mas quando chega o momento, ele bate as asas e desliza, como se tivesse nascido em pleno ar. O que você define como insegurança e imaturidade, eu definiria como inquietação, autoquestionamento, surpresa pela descoberta. E estes são sentimentos de quem está pronto para voar”.

José Roberto Gomes da Silva - Outubro/04 


\section{Resumo}

Rosário, Leila Curty Siqueira Moreno; da Silva, José Roberto Gomes (Orientador). Inserção de Políticas de Propriedade Intelectual nas Instituições de Ensino Superior: O Caso PUC-Rio. Rio de Janeiro, 2006. 136p. Dissertação de Mestrado - Departamento de Administração, Pontifícia Universidade Católica do Rio de Janeiro.

Inseridas em ambiente extremamente competitivo, frente às novas tecnologias e à redução contínua dos investimentos governamentais em pesquisa e desenvolvimento, as Instituições de Ensino Superior (IES) são instadas a interagir, constantemente, com vários órgãos governamentais e entidades privadas, por meio de parcerias que visam à realização de pesquisas básicas e aplicadas. Essa necessidade contribui, por outro lado, para o avanço tecnológico do país, melhorando sua competitividade, frente à inevitável globalização da economia, por meio de inovações e da transferência de tecnologia. Neste contexto, a definição e manutenção de políticas de Propriedade Intelectual (PI) passam a ser um requisito para a sobrevivência de qualquer instituição que investe em pesquisa e desenvolvimento tecnológico, por representar uma condição mandatória para o seu sucesso na transferência do conhecimento gerado para a sociedade, colaborando para a inserção e sustentabilidade das organizações brasileiras e do próprio país no mercado, face às regras que norteiam a competitividade global e fazer jus, em contrapartida, ao recebimento de recursos que ajudam a manter as suas atividades de pesquisa. No caso das IES, em geral, este é um desafio especial, na medida em que são organizações com características específicas, talvez nem sempre propícias à implantação de uma política de PI. Para as IES privadas, isto pode representar um caminho essencial para a sustentabilidade das atividades de pesquisa, dada a necessidade crescente de gerarem seus próprios recursos. O objetivo desta pesquisa é o de identificar requisitos, oportunidades e dificuldades organizacionais para a implementação de uma política de PI em uma IES de gestão privada, no Brasil. O objeto de estudo foi o caso da PUC-Rio, uma das mais tradicionais instituições de pesquisa no país. A metodologia fundamenta-se na percepção de diferentes indivíduos envolvidos nas atividades de pesquisa e desenvolvimento. Os resultados apontam que não há uma homogeneidade acerca da importância e da problemática da gestão de PI entre os participantes da pesquisa, bem como predomina a opinião de que a criação e implementação de uma política de PI não pode ser algo determinado verticalmente, de cima para baixo, pela instituição, mas algo que deve emergir ou ser aceito pelos atores da própria atividade de pesquisa e desenvolvimento, institucionalizando-se após amplo debate entre eles.

\section{Palavras-chave}

Gestão Universitária; Gestão do Conhecimento nas IES; Gestão da Propriedade Intelectual; Propriedade Intelectual; Comercialização e Transferência de Tecnologia; Inovação. 


\section{Abstract}

Rosário, Leila Curty Siqueira Moreno; da Silva, José Roberto Gomes. (Advisor). Intellectual Property Policy in High Educations Institutions: The PUC-Rio Case. Rio de Janeiro, 2006. 136p. MSc. Dissertation Departamento de Administração, Pontifícia Universidade Católica do Rio de Janeiro.

Institutions of undergraduate and graduate studies are in an extremely competitive environment, facing new technologies and the continuous government investment reductions in research and development. They must interact constantly with several governmental institutions and private entities searching partnerships in order to make feasible basic and applied research. On the other hand, these efforts contribute to the technological advancement of the country, improving its competitiveness to face the inevitable economy's globalization, throw technological transfers and innovation. In this context, the significance and maintenance of intellectual properties (IP) policies become a requisite for the survival of any institution that invests in technological development research. It also represents a mandatory condition for the success of knowledge transfer for the benefits to the sustainability of Brazilian organizations and the insertion of itself in the marketplace, taking into account the global competitiveness rules and proving at the same time that the receipt of resources that assist research activities were well worth it. This is a challenge, especially in the case of IES since they are organizations that have specific characteristics that may not be the best scenario for IP policies. For the private IES, this can represent an essential path for the sustainment of its research activities, given the growing need for themselves generating its own resources. The objective of this research at is to identify organizational requisites, opportunities and difficulties for the implementation o IP policies in a private managed IES in Brazil. The Case study is the case of PUCRio, one of the most traditional research institutions in the country. The methodology bases on the perception of different individuals involved in research and development activities. The results point that it does not have a homogeneity concerning the importance and problematic of IP management between the participants of the research, as well as predominates the opinion of that the creation and implementation of IP policies cannot be something determined vertically, top down, by the institution, but should come about or be accepted by its own research and development activities actors, and that its implementation occurs after extensive debate between them.

\section{Keywords}

University Management; Knowledge Management in the IES; Intellectual Property Management; Intellectual Property; Transfer Technology and Commercialization; Innovation. 


\section{Sumário}

1. Definição do Problema 14

1.1. Introdução 14

1.2. Objetivos Final e Intermediário 18

1.3. Delimitação do Estudo 19

1.4. Relevância do Estudo 19

1.5. Estrutura da Dissertação 20

2. A Dinâmica das Universidades 22

2.1. A Problemática Atual da Gestão Universitária no Brasil 22

2.1.1. As Instituições de Ensino Superior no Contexto Atual 23

2.1.2. A Gestão do Conhecimento nas Instituições de Ensino Superior 29

2.2. A Universidade como Organização 30

2.2.1. A Universidade como Organização de Finalidades Múltiplas 30

2.2.2. A Universidade como Organização Especializada 31

2.2.3. Centros de Poder em Universidades 32

2.2.3.1. Modelo Colegial 33

2.2.3.2. Modelo Burocrático Profissional 34

2.2.3.3. Modelo Político $\quad 35$

2.2.3.4. Modelo Anárquico $\quad 35$

2.2.3.5. Modelo Adhocrático 36

2.3. Cultura Organizacional nas Universidades 37

3. Conhecimento e Propriedade Intelectual nas Universidades 41

3.1. A Gestão do Conhecimento 41

3.1.1. Importância do Conhecimento 43

3.1.2. Tipos de Conhecimento 44

3.1.3. Tecnologias na Gestão do Conhecimento 47

3.2. O Falso Paradoxo: Proteção x Disseminação do Conhecimento 49

3.3. A Gestão da Propriedade Intelectual 50

3.3.1. Noções Gerais de Propriedade Intelectual 51

3.3.2. Sistema Internacional da Propriedade intelectual 55

3.3.3. A Comercialização dos Bens Intelectuais 58

3.3.4. Comercialização de Bens Intelectuais: Tendências Atuais e Impactos Econômicos 63

3.3.5. O Conflito de Interesses 65

4. Metodologia $\quad 69$

4.1. Tipo de Pesquisa 69

4.2. Universo, Escolha do Caso e Seleção de Sujeito 70

4.3. Coleta de Dados $\quad 70$

4.4. Tratamento dos Dados

4.5. Limitações do Método $\quad 74$

4.6. Atendimento aos Objetivos da Pesquisa $\quad 75$ 
5. Resultados $\quad 77$

5.1. Instituição Estudada

5.1.1. A Pontifícia Universidade Católica do Rio de Janeiro (PUC-Rio) 77

5.1.2. O Modelo PUC-Rio $\quad 79$

5.1.3. A Gestão da Propriedade Intelectual na PUC-Rio 82

5.1.4. O ENPI da PUC-Rio $\quad 84$

5.2. A Percepção dos Entrevistados sobre PI na PUC-Rio 87

5.2.1. A Importância da Gestão da PI para as Universidades 87

5.2.2. A Visão Geral sobre a PI na PUC-Rio 88

5.2.3. De Quem é a Propriedade dos Bens Intelectuais gerados na
Universidade

5.2.4. A Influência de Políticas de Propriedade Intelectual na Missão da Universidade $\quad 91$

5.2.5. As Dificuldades de Mudança da Cultura na Universidade 92

5.2.6. Os Aspectos que Podem Impactar Positiva e Negativamente a

Assimilação de Políticas de PI na PUC-Rio 94

5.2.7. Os Aspectos Organizacionais que Precisam ser Gerenciados de

Forma mais Efetiva para a Absorção de Políticas de PI 97

5.2.8. Os Processos de Produção do Conhecimento na Universidade e o Papel dos Atores Envolvidos nestes Processos 98

5.2.9. A Dinâmica de Interação entre Departamentos 101

5.2.10. As formas mais adequadas para a adesão/comprometimento dos professores/pesquisadores acerca da PI e suas particularidades na

Universidade

5.2.11. A Localização do Escritório de PI na Estrutura Organizacional da PUC-Rio

5.2.12. A Integração entre a Gestão da PI e a Gestão das Outras

Atividades da Universidade $\quad 106$

5.2.13. A Influência das Práticas de Gestão de Pessoas na Universidade 107

6. Conclusão e Recomendações 110

6.1. Conclusão 110

6.2. Recomendações 114

Referências bibliográficas 116

$\begin{array}{lr}\text { Anexo } 1 & 120\end{array}$

$\begin{array}{ll}\text { Anexo } 2 & 131\end{array}$

$\begin{array}{ll}\text { Anexo } 3 & 133\end{array}$ 


\section{Lista de Figuras}

Figura 1: Processo de Construção da Espiral do Conhecimento

Figura 2: Universidade, transferência tecnológica e comercialização de bens intelectuais

Figura 3: Requisitos Organizacionais 71

Figura 4: Tratamento das Entrevistas 73

Figura 5: Triangulação de Dados 75

Figura 6: Organograma da PUC-Rio 81

Figura 7: Estrutura da PUC-Rio 86 


\section{Lista de quadros}

Quadro 1: Perfil de Entrevistados

\section{Lista de tabelas}

Tabela 1: Atendimento aos Objetivos da Pesquisa 